\title{
Application of Selected Reverse Engineering Procedures Based on Specific Requirements
}

doi:10.2478/mape-2021-0007

Date of submission to the Editor: $04 / 2021$

Date of acceptance by the Editor: 05/2021

MAPE 2021, volume 4, issue 1, pp. $75-85$

Mária Hrčková

ORCID ID: 0000-0002-9103-9036

Technical University in Zvolen, Slovak Republic

Pavol Koleda

ORCID ID: 0000-0002-7369-0589

Technical University in Zvolen, Slovak Republic

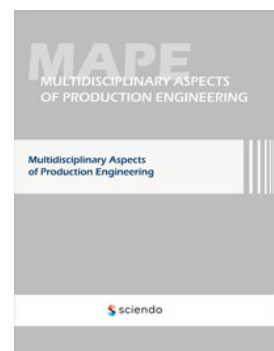

\section{INTRODUCTION}

At present, reverse engineering is considered an important methodology in the product design process, with emphasis on inverse methods and deduction (Zivkovic et al., 2018, Durna et al., 2020). Zivkovic's work confirms the fact that reverse engineering is the opposite of mechanical engineering. Reverse engineering uses an existing object (Paulic et al., 2014). The process of measurement, analysis and testing creates a digital model from a real object, which is identical to the original (Li et al., 2002, Várady et al., 1997). The main areas of its use are: production of parts that do not have production drawings available, repair or replacement of worn parts and creation of prototypes of parts for the purpose of performing analyses (Wang, 2010). Due to various technological advances, reverse engineering has shown a growing potential in various application areas over the last decade. It is one of the technologies that provide the possibility of shortening the development cycle of products, as well as increasing their quality (Raja and Fernandes, 2008), (Kumar et al., 2013). Rapid prototyping is a direct follow up to reverse engineering. It is an innovative technology that aims to quickly create a prototype that allows the analysis of shapes, dimensions, as well as visual inspection and ergonomic evaluation (Anwer and Mathieu, 2016). Implementation of reverse engineering at a quality level presupposes knowledge from several scientific disciplines.

\section{METHODOLOGY OF RESEARCH}

At the Faculty of Technology of the Technical University in Zvolen, in order to using modern technologies in the teaching process, we began to build a reverse engineering laboratory. In order to verify its equipment and functionality, we performed tasks, that should have verified its functionality and determined what are the possibilities and areas of its utilisation. The tasks would also help us determine what other equipment might be appropriate to add to the laboratory. The tasks were diverse. They included evaluation of a wear rate for a tool used for the elimination of undesirable woody plants, creating a replacement for a 
worn part through 3D printing (cooperation with KRUP) and a creation of a 3D model of a damaged shape-complex part without drawing documentation by various processing methods.

\section{Scanner selection}

The principle of most scanning devices is based on sensing the surface of the object in discrete points, so that the digitized object is represented in the computer by a large number of points in the space of the so-called cloud points (Babjak, 2006). The cloud of points that we obtain from a physical object (Paulic et al., 2014) represents the shape of the object and by modifying it we achieve the creation of a 3D model of the object (Sokól and Cekus 2017). The offer of scanners is extensive and when choosing a specific type, we should choose a scanner that will meet our requirements in terms of mobility, speed and accuracy of scanning, but also affordability. Another significant criterion is the size and complexity of the part, as well as the ability to access complicated sections of the part (Koelman, 2010), which we are going to scan. Before the scanning process itself, it is necessary to create suitable conditions for scanning: to secure the scanned object against unwanted movement, create adequate lighting conditions (low brightness), in case of unwanted reflections, modify the object with a matt spray or coat it with powder, or gently roughen it. (Valerga et al., 2015). Climatic conditions (temperature and humidity) also affect scanning accuracy.

\section{Tools wear}

We had two tools of the same type available to solve the tools wear task. One was used in the work process (had visible signs of wear) and the other (identical to the first) was completely new. No technical documentation was available for these tools.

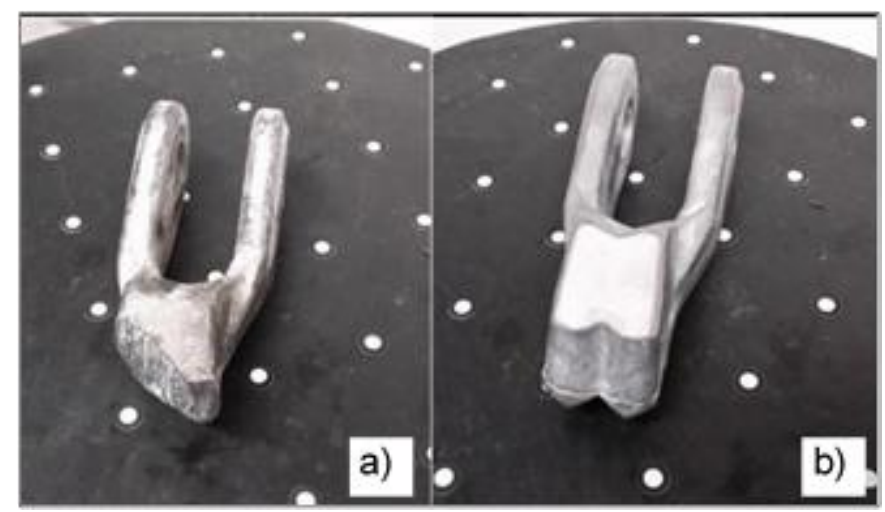

Fig. 1 Tools for mulching: a) worn out, b) new

The dimensions of the tools were not large, so we used the DAVID Laserscanner Starter-Kit DL-SET01 scanning system to scan them. This device is not expensive, offers easy operation and high mobility. It uses laser beams to scan. 
We had to calibrate the device before scanning. We used a calibration panel with plotted points.

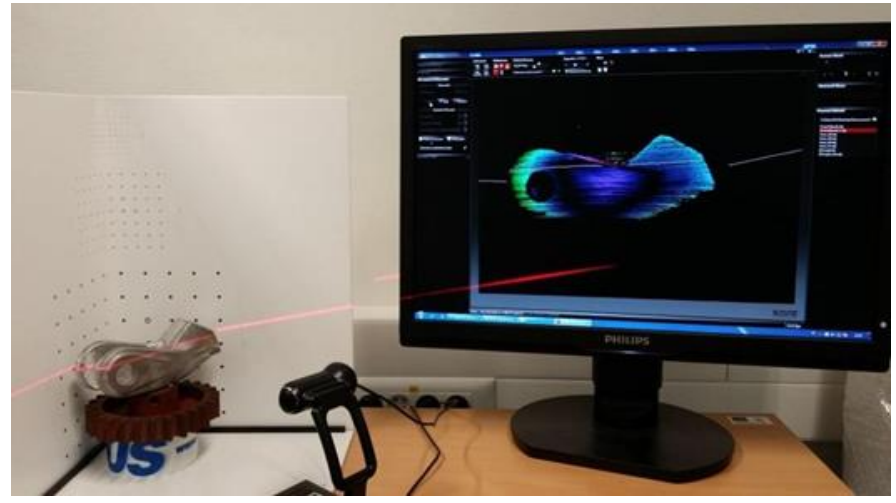

Fig. 2 Workplace for 3D scanning

During the scanning itself with the DAVID system, we recorded its shape by smooth movement of the laser beam over the surface of the part. By gradually rotating the tool around its axis, we obtained 9 scans. Then we added 2 scans of the top and 1 scan of the bottom area. The scans obtained consisted of a cloud of points that also contained some visible errors. We modified the scans (removal of visibly wrong points and excess areas) in order to reach a good quality of the final result. Subsequently, we merged the partial scans. When merging, the program found common reference points for partial scans and created a 3D scan of whole object. During its creation, we closed all the openings on the object, which were created by imperfect scanning, and at the same time we smoothed the resulting scan. We saved the created 3D scan in .obj format, for the purpose of its further use in other CAD tools. The result of the scanning and subsequent adjustments were two models of the working tool (the tool before the first use and the worn tool). Both are shown in Fig. 3.
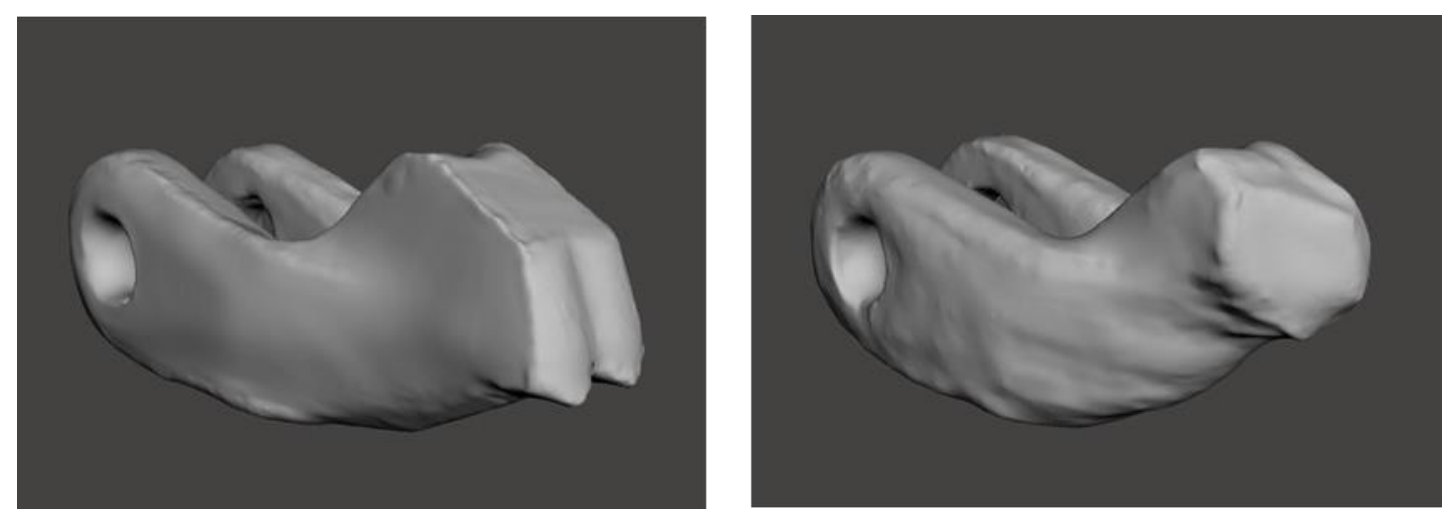

Fig. 3 Scans of new and worn work tool

We compared the obtained models in terms of their dimensions before and after wear, in order to determine the relationship between the size of tool wear and its weight loss with the time of tool use. The comparison was made by program CloudCompare. The results of the comparison are shown in Fig. 4. 

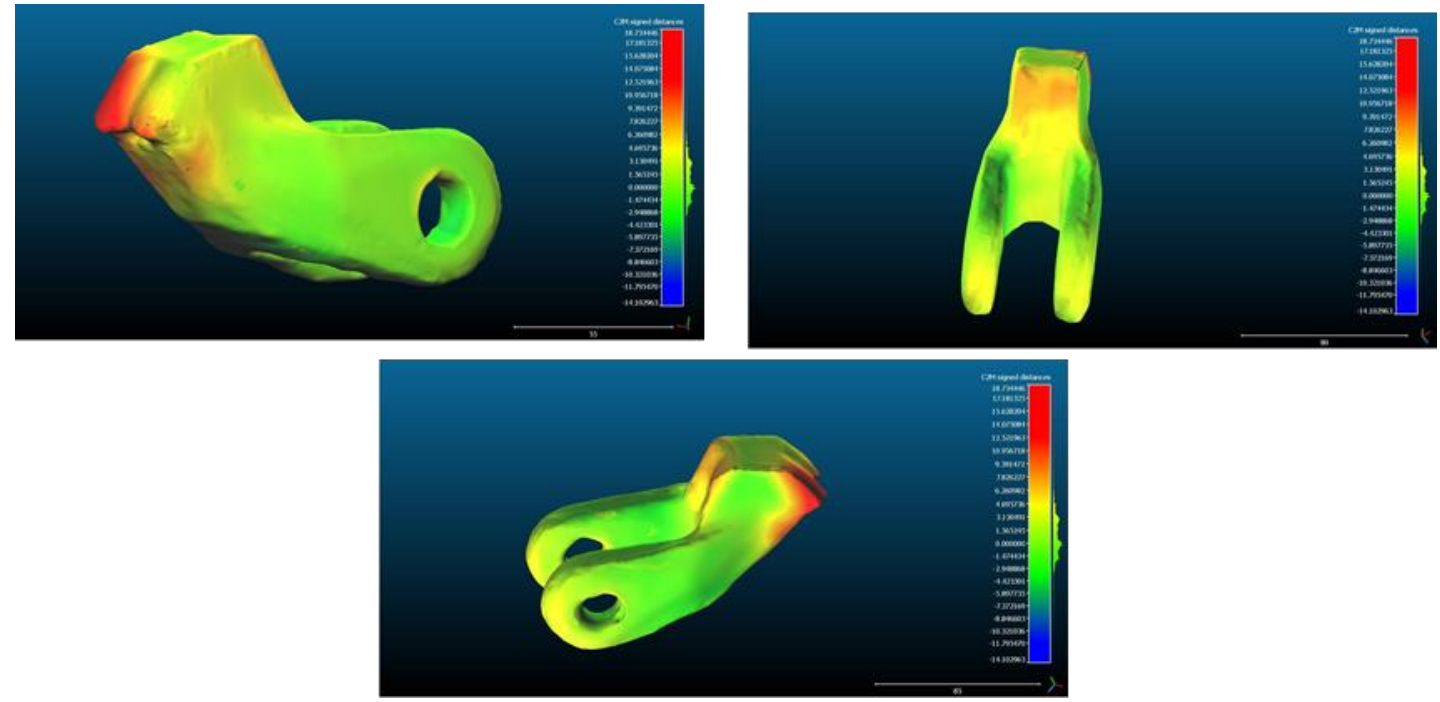

Fig. 4 The result of a comparison of a new and worn tool in CloudCompare

\section{Production of a part that will replace a worn part for the company KRUP}

Part of the machinery of KRUP is a single-purpose barley processing machine. The parts that are most stressed during production include the shaft and the cutter. And it was these two parts, due to their high wear, that the company needed to replace with new ones. The parts did not have complete drawing documentation. A quick and comprehensive solution was to create prototypes of parts using reverse engineering and rapid prototyping techniques and at the same time create their drawing documentation. In order to be able to continuously check the scanning results, we measured the basic dimensions of the components with conventional gauges. Subsequently, we proceeded to scan the parts using the DAVID system. Despite the consistent scanning process and its multiple repetition, the quality of the scans was insufficient. The overall model after scanning had basic shape features, but the capture of details was of poor quality. From the obtained data it was not possible to create a goodquality reconstruction of the models of the parts (Fig. 5).
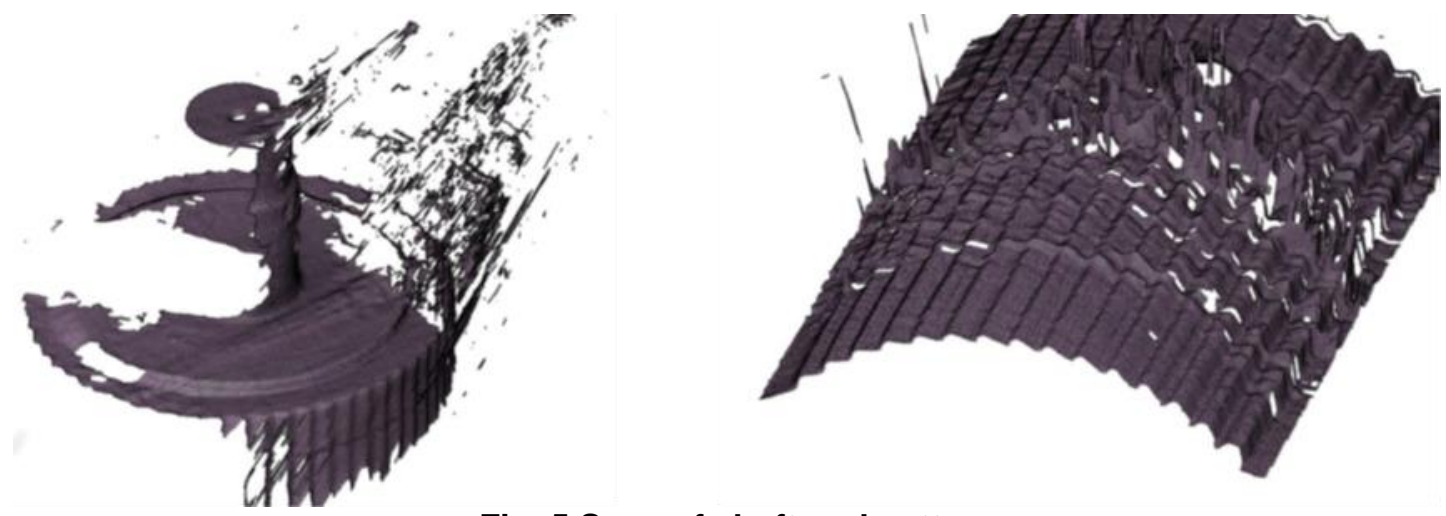

Fig. 5 Scan of shaft and cutter

The main problem was the low resolution in the scanning process, as well as the size of the scanned object. As an alternative solution, we used a threedimensional coordinate method - photogrammetry. This method uses several 
digital photographs of the object from different perspectives as the main medium (Čmarada and Hrčková, 2012). It is based on the principle of triangulation, but also uses other disciplines, such as optics and projective geometry. We photographed the components from different angles and at different angles of rotation of the camera. We had a total of 114 photos available, which we uploaded to program ReCap from Autodesk. The program created a digital 3D scan of the object based on the unification of significant points. Before exporting it to the modelling program, it was necessary to set the scan scale. We used the measured basic dimensions of the part to set it.
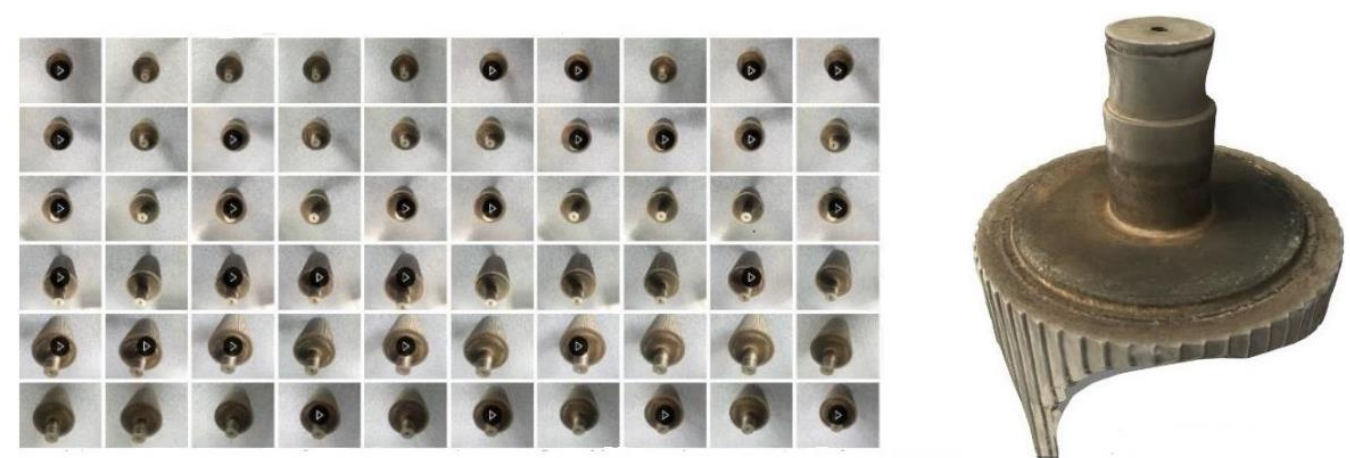

Fig. 6 Samples of photographs and a 3D model of a shaft created by photogrammetry

We further modified the completed scan in the Fusion 360 program. We had to solve the insufficient quality of the scan by additional measurements and calculations (it was mainly the size and angles of the teeth). The calculations were based on data obtained by 3D scanning: forehead angle, back angle, wedge angle, length, height and tooth radius. We created 3D models by combining the above procedures. We exported the models in STEP format to SolidWorks, and used the program to create the drawing documentation. We also verified the quality of the models by simulating different types of their stress. Based on the request of company KRUP we made prototypes of the shaft and cutter using rapid prototyping technology. The printing of the prototypes was realized on an FDM 3D printer CR-10 from the company Creality. This type of printer required the export of models in STL format. The process of 3D printing of the prototype was fully automatic after setting the printing parameters.
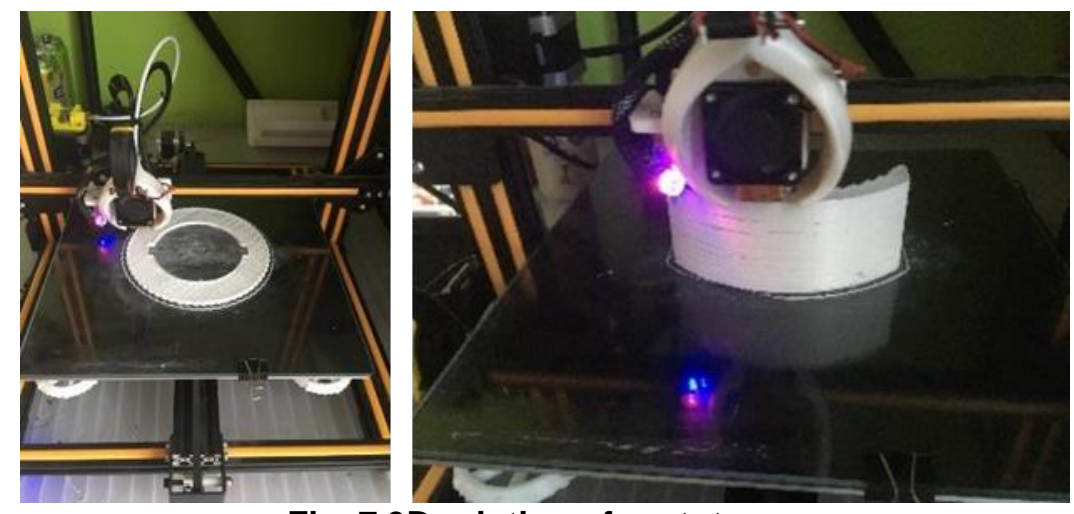

Fig. 7 3D printing of prototypes 


\section{D model of a shape-complex part}

Based on the negative experience with scanning objects of larger dimensions, we started cooperating with the company CEIT, a.s. Žilina.

We used the Faro Edge ScanArm ${ }^{\circledR}$ HD device, owned by the CEIT company, to scan a shape-complex part - a carburettor (Fig. 8 Scanned part (carburettor). It is a 7-axis articulated measuring device. Said scanner at work makes it possible to combine contact measurement using a touch measuring sensor and contactless measuring, which is performed by means of a laser scanning head. The device has an arm length of $1.8 \mathrm{~m}$, which was sufficient for our task.

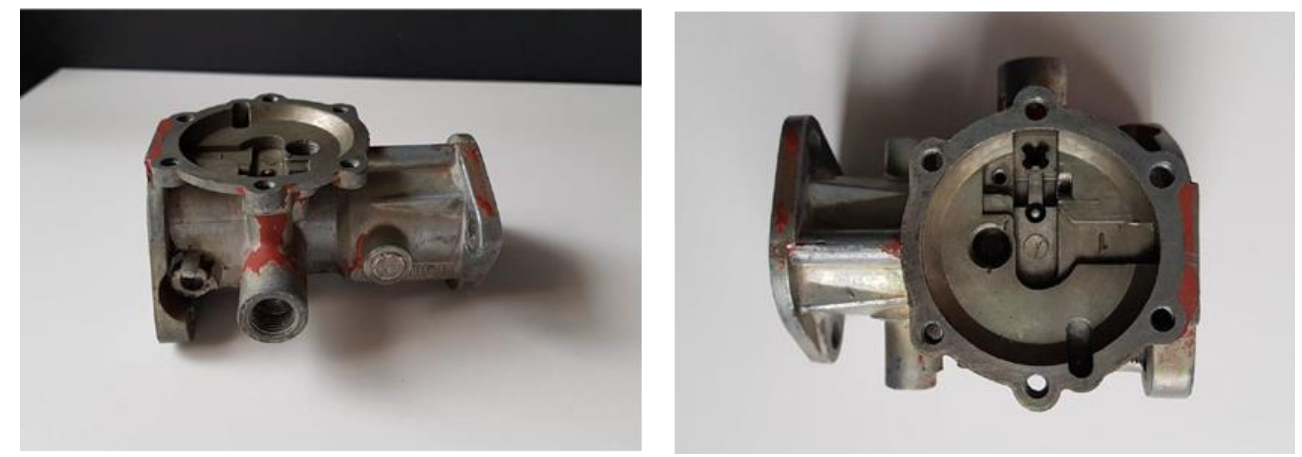

Fig. 8 Scanned part (carburettor)

The prepared (cleaned and degreased) part together with the scanning device were firmly attached to the work table. Subsequently, we calibrated the scanner using special tools supplied by the manufacturer. The entire scanning process took place in program InnovMetric PolyWorks (Fig. 9).
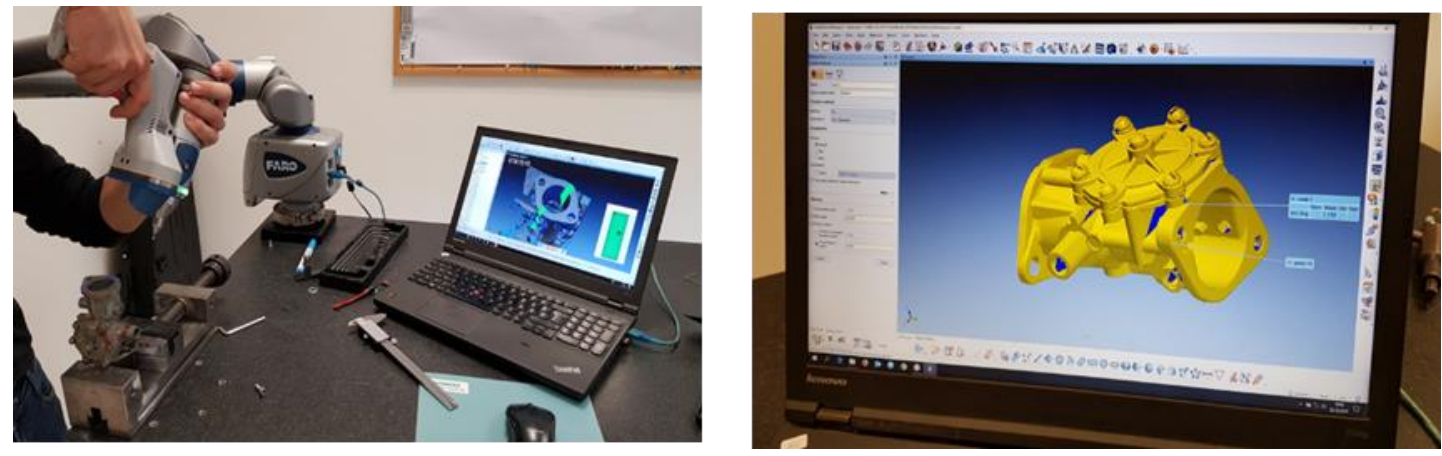

Fig. 9 Scanning progress

At the beginning we defined the coordinate system. The method of attaching the part did not allow scanning from all sides, and therefore we performed the scanning itself in two stages. In the first stage, we measured the basic planar surfaces and circular parts with a touch sensor. In the second stage, we used non-contact laser scanning, thanks to which we added the details of the part (holes, rounding, protrusions, etc.) to the basic surfaces. We were able to continuously observe the entire scanning process on a computer. Since it was a shape-complex part, it was necessary to scan uneven surfaces from several angles. We obtained a separate 3D scan for each component fixation. We 
unified the obtained 3D scans. Due to the complexity of the part, the unified 3D scan was of high quality, but not perfect. It contained places like corners and deep holes, that could not be recorded. We modified the scan in the Geomagic Wrap program from the company 3D Systems, which is intended for editing and processing data in the form of a point cloud. It was mainly the removal of imperfections in the form of holes and unclosed surfaces.

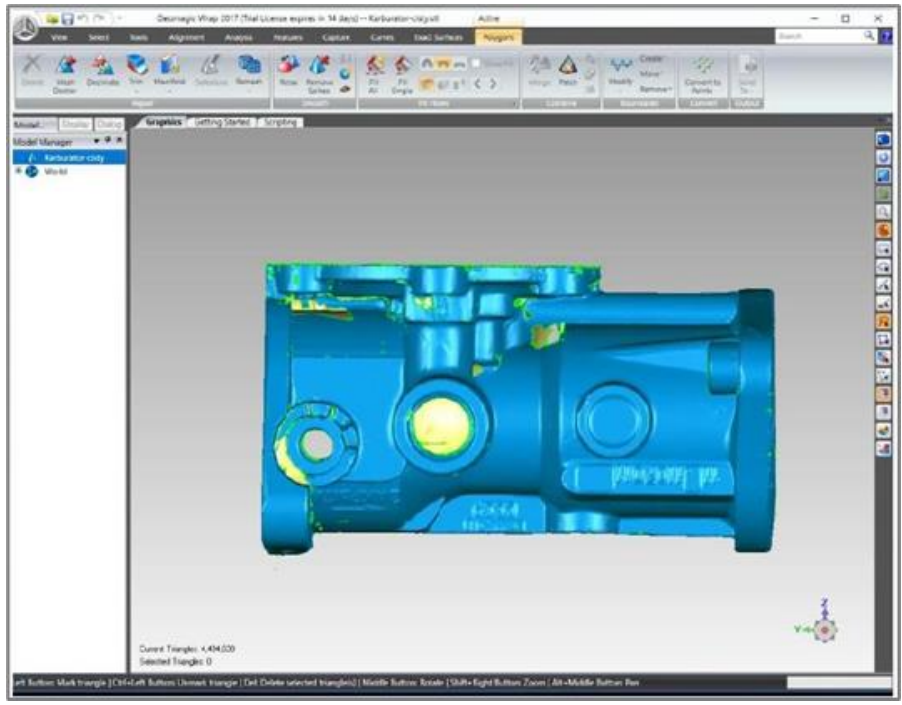

Fig. 10 3D model of the part before removing the imperfections

Subsequently, we proceeded to the reconstruction of the 3D scan into a CAD model in the Geomagic Design X program from the company 3D Systems, so that we could prepare the drawing documentation. In order to achieve the highest possible quality, we have applied two different approaches. One of them was based on the AutoSurface function, based on which a closed network of points was created on the surface of the 3D scan. It copied the contours and the initial shape, which allowed us to create a 3D surface model of the part, which we converted to a volume model.
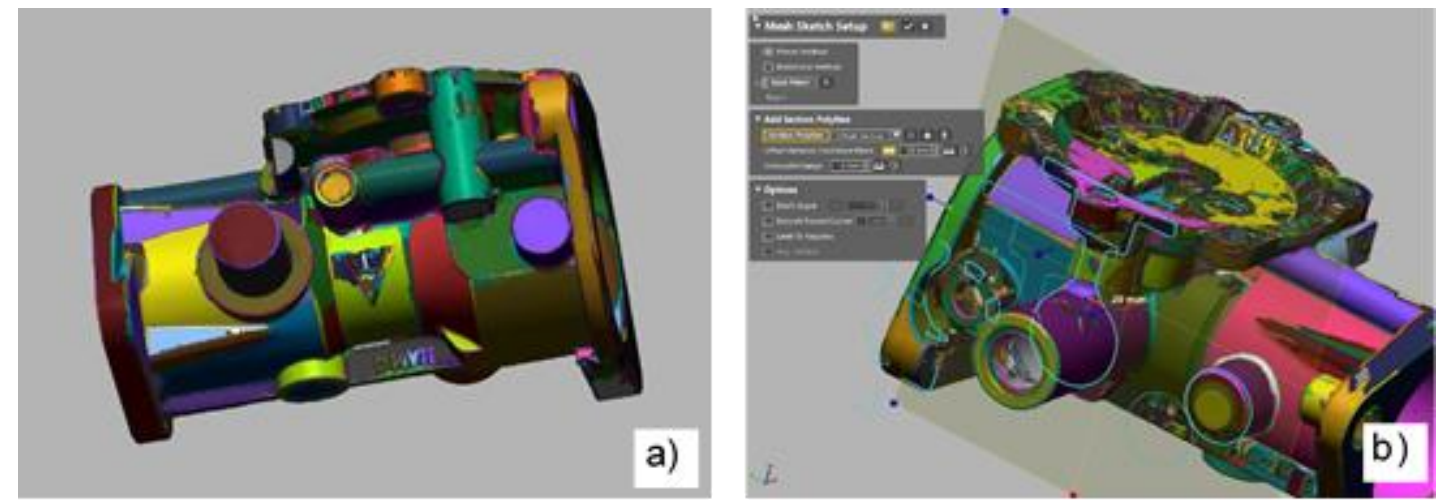

Fig. 11 Reconstruction of the part:

a) automatic creation of volume segments, b) use of sections

The second approach was based on the reconstruction of the 3D scan by conventional modelling methods. The starting point was the identification of 
basic errors and geometric shapes with the Geomagic Design X program. We used automatic volumetric modelling and sections of 3D scan (Fig. 11). By combining automatic functions and common methods, we created a CAD model of the scanned part.
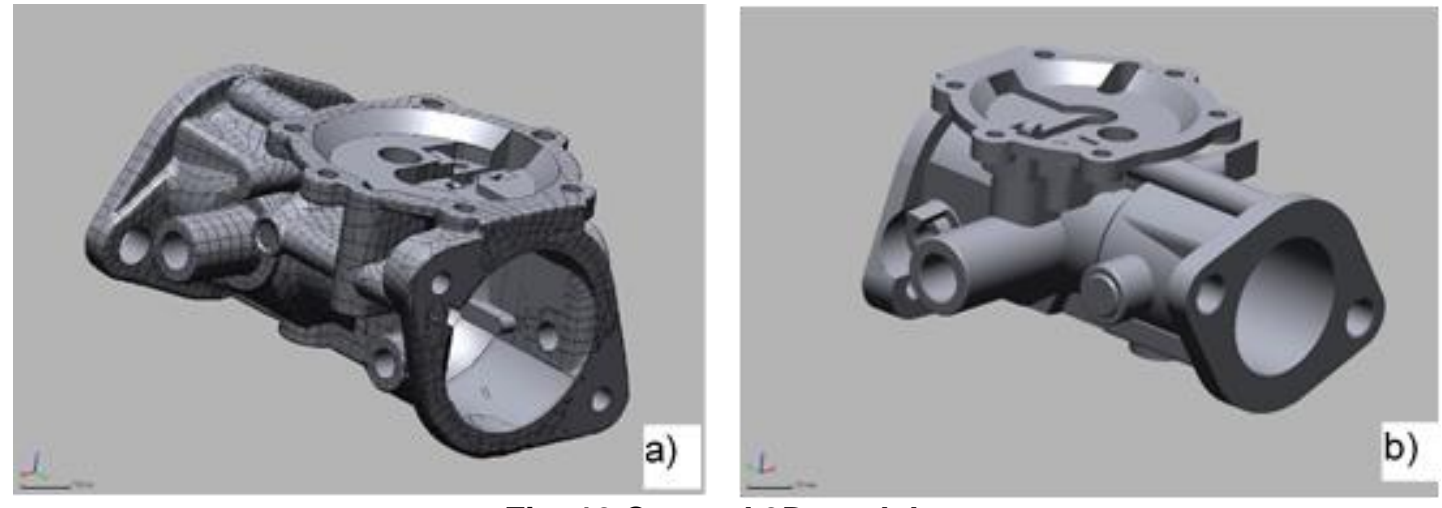

Fig. 12 Created 3D models:

a) method of AutoSurface b) direct reconstruction

We compared the 3D models created by different procedures with the original scan in order to find out the differences.
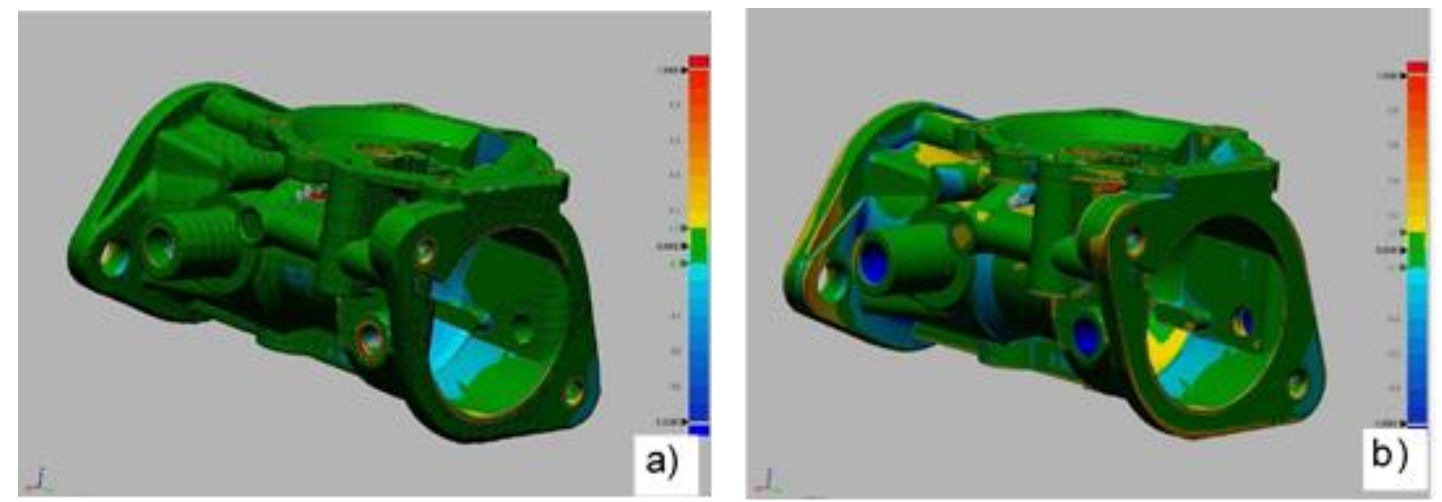

Fig. 13 Comparison of the original scan with the created model a) method of AutoSurface b) model created by classical modelling

Deviations are expressed in the form of a colour map. Locations where no deviations were found are represented by green colour.

\section{DISCUSSION}

When comparing the new and worn tool, it was confirmed that the largest deviations were in the cutting part of the tool, specifically in the area of the right tooth. The maximum deviation of the worn tool from the new tool was $18 \mathrm{~mm}$. Since the wear occurred in the cutting part, the clamping part of the tool could be used to evaluate the accuracy of the 3D scan and to determine the inaccuracies that occurred during this process. We evaluated the deviations on the side walls of the clamping arms, where they reached a value of up to $1 \mathrm{~mm}$, then at the ends of the clamping arms in the arcuate parts, where it was up to 3 $\mathrm{mm}$, and in the clamping holes at the ends of the arms, where the deviation 
ranged from 0 to $1 \mathrm{~mm}$. We then compared the volume and weight of the two tools and found a difference in volume of $18.68 \mathrm{~cm}^{3}$ and weight of $146.7 \mathrm{~g}$. The most extensive wear was in the area of the cutting part. Based on the above analysis and repetition of measurements at regular intervals during the use of the tool, it is possible to determine the length of the period of time in which it is recommended to use the tool in working mode. After the recommended time period, the size of tool wear would significantly affect the work performance of the machine that uses the tool, and therefore it is necessary to replace it.

When solving the requirement for the preparation of drawing documentation and prototypes of parts for the company KRUP we have found that parts that contain a lot of small details are difficult to scan properly. To create a usable scan, we would need to have the equipment available to enable various high-resolution scanning methods. The scanners we had did not meet these requirements and therefore we had to use the method of photogrammetry in combination with technical calculations. This significantly increased the time required to solve the task. By combining photogrammetry, measurements and calculations, we managed to create 3D models of parts, which allowed us to realise simulations, creating of prototypes and drawing documentation. We handed over the prepared technical documentation and finished prototypes of the parts to the company KRUP, which is looking for a supplier of these parts on the basis of the drawing documentation.

Scanning and creating a model of a shape-complex part was a significantly more demanding process than it is with simple shape objects. It was difficult to accurately scan deep holes and corner joints of surfaces. Due to the complexity of the shape, several imperfections arose in the 3D scan that needed to be corrected. This increased the time required for the reconstruction itself. We tried various procedures when creating the finished 3D model. We compared the created 3D models with the original scan. The dimensional deviations found in the model created by the Auto Surface method were minimal. The most significant deviations were in places that were subsequently modified, such holes. When comparing the original scan with the model created by classical modelling, the average deviations ranged from 0 to $0.2 \mathrm{~mm}$. Larger dimensional deviations occurred at sharp edges, holes of great depth, and in places where the original part was significantly worn. The choice of the method for creating a 3D model of a shape-complex parts depends on various factors: the expected time of reconstruction, the required level of quality, the purpose of use of the completed model, the quality of the scanned part (Kassai 2019). If the goal is a quick reconstruction and there are no high requirements for the surface quality of the resulting model, based on the achieved results for scanning shapecomplex parts we recommend to use the so-called Auto Surface method. The deviations of the 3D model created by this method compared to the 3D scan were smaller than when creating the model by direct modelling. In the case of a high degree of damage to the component, as well as the requirement to create 
high-quality drawing documentation, a method of direct remodelling is more appropriate.

\section{CONCLUSION}

Based on the realisation of the solved tasks, we can conclude that the laboratory that we have at our disposal is operational and provides wide possibilities for solving various tasks in the field of reverse engineering, reflecting the requirements of the faculty as well as tasks from practice. It would be appropriate to supplement the laboratory with a scanning device that enables scanning of larger objects and scanning at a higher resolution.

\section{ACKNOWLEDGEMENTS}

This paper was prepared as part of project KEGA 006STU-4/2021: „Progressive form of interdisciplinary education and supporting the subject-specific study development at universities".

\section{REFERENCES}

Anwer, N. and Mathieu, L. (2016) From reverse engineering to shape engineering in mechanical design, CIRP Annals - Manufacturing Technology, Volume 65, Issue 1, 2016, pp. 165-168, ISSN 0007-8506, http://dx.doi.org/10.1016/j.cirp.2016.04.052.

Babjak, Š (2006) Plánovanie reverzného inžinierstva $v$ procese rýchleho vývoja výrobkov II, Transfer inovácií, Košice, issue 9, pp. 62-64, ISBN 80-8073-701-0

Čmarada, M. and Hrčková M. (2012) Trojrozmerné skenovacie systémy, In: Strojárstvo: mesačník o strojárstve, issue 4, pp. 6-9, ISSN 1335-2938.

Durna, A., Fries, J., Hrabovsky, L., Sliva, A., Zarnovsky J. (2020) Research and Development of Laser Engraving and Material Cutting Machine From 3D Printer. Management Systems in Production Engineering. Volume 28, issue 1. pp. 47-52. DOI: $10.2478 / \mathrm{mspe}-2020-0008$

Koelman, H. J. (2010) Application of a photogrammetry-based system to measure and re-engineer ship hulls and ship parts: An industrial practices-based report, Computer-Aided Design, Volume 42, Issue 8, pp. 731-743. https://doi.org/10.1016/j.cad.2010.02.005.

Kassai., M. (2019) Využitie techník reverzného inžinierstva pri rekonštrukcii tvarovo zložitej súčiastky, Diplomová práca, Zvolen: Technická univerzita vo Zvolene. 2019. $83 \mathrm{~s}$.

Kumar, A., Jain, P. K. and Pathak, P. M. (2013) Reverse Engineering in Product Manufacturing: An Overview. DAAAM International Scientific Book, pp. 665-679.

Li, L., Schemenauer, X., Peng, Y. and Gu, P. (2002). A reverse engineering system for rapid manufacturing of complex objects, Robotics and Computer-Integrated Manufacturing, Volume 18, Issue 1, 2002, pp. 53-67, ISSN 0736-5845, http://dx.doi.org/10.1016/S0736-5845(01)00026-6.

Paulic, M., Irgolic, T., Balic, J., Cus, F., Cupar, A., Brajlih, T. and Drstvensek, I. (2014). Reverse Engineering of Parts with Optical Scanning and Additive Manufacturing, Procedia Engineering, Volume 69, 2014, pp. 795-803, ISSN 1877-7058, http://dx.doi.org/10.1016/.proeng.2014.03.056

Raja, V. and Fernandes, K. (2008) Reverse Engineering: An Industrial Perspective. Springer-Verlag London 2008. 242 s. ISBN 978-1-84628-855-5.

Sókol, K. and Cekus, D. (2017) Reverse Engineering as a Solution in Parts Restoration Process, Procedia Engineering, Volume 177, pp. 210-217. https://doi.org/10.1016/j.proeng.2017.02.191. 
Valerga, A. P., Batista, M., Bienvenido, R., Fernández-Vidal, S. R., Wendt, C. and Marcos, M. (2015) Reverse Engineering based Methodology for Modelling Cutting Tools, Procedia Engineering, Volume 132, pp. 1144-1151. https://doi.org/10.1016/j.proeng.2015.12.607.

Várady, T., Martin, R. R. and Cox, J. (1997). Reverse engineering of geometric models - an introduction, Computer-Aided Design, Volume 29, Issue 4, 1997, s. 255-268, ISSN 0010-4485, http://dx.doi.org/10.1016/S0010-4485(96)00054-1.

Wang, W. (2010) Reverse Engineering Technology of Reinvention. CRC Press Taylor \& Francis Group, an Informa business Boca Raton 2010. 357 p. ISBN 978-1-43980630-2. https://doi.org/10.1201/EBK1439806302.

Zivkovic, S., Cerce, L., Kostic, J., Majstorovic, V., Kramar, D. (2018) Reverse Engineering of Turbine Blades Kaplan's type for Small Hydroelectric Power Station, The 15th CIRP Conference on Computer Aided Tolerancing - CIRP CAT 2018. Milan, Italy, Volume 75, pp. 379-384, https://doi.org/10.1016/j.procir.2018.04.037.

\begin{abstract}
The paper describes a solution of reverse engineering tasks using the equipment of the laboratory of the Technical University in Zvolen. The first task was linked to evaluation of a wear rate of the tool used to for mulching and elimination of unwanted wood or weed vegetation. The obtained data will be used as a base line for determination of the time interval for the tool replacement. We developed a prototype of components and their drawing documentation for a single-purpose machine for cutting barley. We created the 3D model using the method of photogrammetry. The finished drawing documentation and prototypes were handed over to the company KRUP. Finally, we identified the most suitable procedures for creating a model of a part with a complex shape. We tested the techniques of editing the point cloud processing, as well as of smoothing the surfaces and automating the creation of partial geometric elements of the model. Based on the properties of the component, which is the starting point of the entire reverse engineering process and from the achieved results, we set recommendations for the selection of appropriate procedures.
\end{abstract}

Keywords: reverse engineering, scanning, 3D model, point cloud 